\title{
The Consumer Juggernaut: Web-based and Mobile Applications as Innovation Pioneer
}

\author{
David G. Messerschmitt \\ Department of Electrical Engineering and Computer Sciences \\ University of California at Berkeley, USA \\ messer@eecs.berkeley.edu
}

\begin{abstract}
As happened previously in electronics, software targeted at consumers is increasingly the focus of investment and innovation. Some of the areas where it is leading is animated interfaces, treating users as a community, audio and video information, software as a service, agile software development, and the integration of business models with software design. As a risk-taking and experimental market, and as a source of ideas, consumer software can benefit other areas of applications software. The influence of consumer software can be magnified by research into the internal organizations and processes of the innovative firms at its foundation.
\end{abstract}

Keywords: Software applications, world-wide web, user interfaces, development, business processes

\section{Introduction}

Consumer software applications target individual members of our society, and provide them with productivity enhancements, fun and entertainment, and ways to interact and collaborate with family, friends, and colleagues. Other distinctive categories of software applications include those that serve organizations (businesses, education, government, military, etc.) and commerce. Consumer software applications can be (and frequently are) exploited in organizational contexts as well. With the advent of the Internet and the Web, as well as new computing platforms such as the smart phone, the space of consumer software applications has in recent years seen an explosion in innovation. Consumer software applications are highly innovative and experimental, and other categories of software can explicitly exploit or benefit from their pioneering spirit.

\section{The Opportunity}

Although the vendor industries in information technology (IT) have increasingly adopted an open innovation model ${ }^{[3]}$, business and enterprise applications remain largely inwardly focused in their innovation. Many large enterprises expend considerable resources for customized solutions designed to meet their special needs or provide competitive advantage, while the number of vendors providing standardized customizable solutions is small. The innovation model within a large

International Conference on Product Focused Software Development and Process Improvement, Oulu, Finland, 15-17 June, 2009. 
company's information systems (IS) organizations falls in Pasteur's quadrant ${ }^{[20]}$, relying on internal experience and expertise to identify specific opportunities for improving efficiency and effectiveness through information technology. Later as more generic needs spread throughout the relevant industry and the competitive advantage of customized solutions is undercut, it is typical to reduce cost and risk by adopting off-the shelf solutions (such as replacing a home-grown accounting system by a commercial enterprise resource planning solution).

In the meantime, consumer software applications have become very dynamic, moving beyond personal productivity and automation of existing functions into pioneering new territory. One characteristic of new technology development is uncertainty $^{[21]}$, which is a anathema to the manager of a large organization but more acceptable to entrepreneurs and early adopters among consumers. These applications are sometimes directly useful in enterprises, but more commonly there are opportunities for capturing innovation and value within enterprises inspired by these consumer technologies.

It is not unexpected that consumer markets would become a technology leader and application driver in software. The extraordinarily large market opportunity, the high competitive energy brought to bear, and the relatively large investments that are possible eventually overwhelm the greater focus of products aimed at specific organizational needs. This has happened previously in other areas of IT. For example, military technology has historically created important spin-offs to civilian and commercial use, the Internet being a premier example. Increasingly military applications have become dependent on commercial technology ${ }^{[1]}$, while specific military needs are increasingly specialized and hence less likely to influence commercial markets. Another example is the supercomputers used for the highest end and most specialized needs imaginable, which today are most commonly built from large numbers of commodity commercial processors ${ }^{[8]}$, those processors at the high end in turn largely justified by gaming and Web server applications. The supercomputer market could never justify investments approaching those already targeted at the commercial market.

In application software for enterprises, for similar reasons it has always been true that outside of specialized areas (such as enterprise resource planning, knowledge management, and applications customized to individual company processes) companies rely on standard commercial solutions at both the application and infrastructure levels. Both specialized solutions and commercial solutions should benefit from an infusion of new ideas.

In what follows we discuss some opportunities for other areas of the application software industry that arise from recent innovations in consumer applications.

\section{The Cutting Edge of Consumer Software}

It is useful to illustrate some areas where consumer software pioneered new innovations by focusing on three major examples.

Gaming has spawned innovations in graphics processors, software graphics, and programming tools. Embodied in gaming, in spite of its lighthearted motivations, is a richness of interaction and user experience that has profound implications for other application areas. Many areas of activity could benefit from such techniques and 
associated technology, suitably adapted and extended. This includes activities in the "real world" with a game-like character ${ }^{[12]}$ and knowledge exploration and training and education ${ }^{[22]}$. SecondLife illustrates a game-like environment with a monetary and market element, and could be a precursor to more blatantly commercial marketplaces. Many other activities can benefit from interface elements like sensors and rich animation.

Social networking applications such as Facebook have moved beyond the view of a software application focused on its the individual users. They treat their membership as a collection of communities, in a model called community networked services ${ }^{[14]}$. Earlier organizational applications focused on coordination of business processes such as customer service have pioneered the service of groups of users, but social networking is defining new ways to support (and more importantly expand) the informal and social needs of its users. As with gaming, many of the activities supported in social networking can be viewed as lighthearted or even trivial, but the general modalities captured therein may be applicable to a variety of serious purposes.

Audio, video, speech recognition are increasingly integrated into applications and help systems. A Google speech-recognition based search function has become popular on the mobile platform, and the ability for all users to post videos for all to see has stimulated a variety of new uses. The text to speech synthesis of the Kindle e-book reader bridges the gap between audiobooks and textual interfaces. Increasingly traditional journalism, product reviews, and help systems rely on video in place of traditional textual interfaces.

The foregoing examples illustrate new functionality that has proven useful to consumers. Innovation has occurred in non-functional areas as well. Although it is not yet well documented, it appears that many of the new Web-based applications have a close connection to their end users in guiding the ongoing evolution of the service, as another concrete example of Pasteur's quadrant innovation ${ }^{[20]}$ driven by end users, as has been common in many industries ${ }^{[24],[25]}$. As a driver for their business models, new services have found ways for users to collectively co-create value through their joint activities, and identified ways for the monetization of that value by the service provider $^{[14]}$. New applications and services are much more likely to be distributed by software as a service $(\mathrm{SaaS})^{[23]}$ than the traditional software download and installation by the user. Mobile platforms, however, have illustrated the value of mixing the download and SaaS models. In a related but different vein, the opportunities from cloud computing ${ }^{[9]}$ have been concretely illustrated by applications that allow consumers to store or backup data and perform processing on remote servers.

\section{Capturing Innovations in Functionality}

Inevitably many of these consumer applications are used within organizations and businesses, whether officially sanctioned and promulgated by an IS organization or informally introduced by the staff. Like the backdoor entry of the personal computer in an earlier era, this allows users to experiment and invent new uses while potentially creating a number of problems such as security holes or data loss. Consumer applications are not designed with specific organizational needs in mind, and in many cases neither do they directly meet compelling organizational needs. How, for example, would many of the video games be compelling? The consumer market is not 
only large, but less risk adverse and more appropriate for experimentation. It can serve as a source of ideas and inspiration, and a place where features can mature and be qualified. By their very nature, consumer applications have broad interest, and as such many of their most useful features are arguably more likely to be incorporated into vendor software than developed internally to organizations. The ideas incorporated therein are particularly applicable to customer-facing systems, and less likely to be incorporated into internal business processes. However, they should be valuable in the extemporaneous and informal processes of an organization, and interorganizational interactions and collaborations ${ }^{[16]}$ as well.

The three areas of innovation listed previously can illustrate this. New modalities of informal communication identified in social networking applications can improve the effectiveness of geography-spanning virtual teams ${ }^{[13]}$, but an even bigger opportunity is to expand the informal lines of communication in an organization ${ }^{[11]}$ that were previously associated with self-limiting physical proximity. Ways in which value can be co-created within a community ${ }^{[14]}$ are clearly applicable to an organizational context. The use of media like audio and video can be dramatically expanded beyond voicemail and formal training videos to enhance communication and reduce some of the drudgery often associated with paperwork and documentation. It is a reasonable hypothesis that these sorts of informal connections among users are more effective than formal initiatives like knowledge management systems in capturing and conveying the tacit knowledge that is a crucially important resource for any effective organization ${ }^{[7]}$. Such informal networks may also help rejuvenate apprenticeship as a supplement to formal training programs.

Clearly there are many unknowns here. Studying the modalities for enhancing communication and collaboration in the consumer marketplace and their outcomes and effectiveness can contribute to understanding of how to achieve similar benefits in more formally structured organizations, and possibility how to restructure these organizations for greater effectiveness as well.

\section{Capturing other benefits}

While consumer applications can provide inspiration on new functionality, there can be other valuable spin-offs as well. A few examples will now be outlined.

One of the major challenges for applications software lies in the maturity of the industry. The earliest and easiest approach, the "low-hanging fruit" if you will, is the automation of existing functions and processes. For example, in the consumer area the earliest applications were word processing and email, functions that simply automated previously manual processes. Gaming and the Web began to introduce functionality not seen previously, and their success is evident. The greatest gains as measured by efficacy (accomplishing what is intended), effectiveness (accomplishing it well), and efficiency (accomplishing it with minimum resources) arise when new uses are found for technology, new uses that take advantage of its special capabilities. There is considerable historical evidence backing up this observation ${ }^{[5]}$. This process seems more evident in consumer software applications, at least recently. As greater understanding is developed into the mindsets and processes behind this, consumer software applications can serve as a model for speeding this process in other domains. 
There are increasing demands on the information systems organization to become more business relevant, and the CIO to assume more of a role of a general business manager ${ }^{[19]}$ that participates in decision making at the executive level. The nature of the business challenges facing a CIO are undoubtedly far different those faced by a consumer application vendor. However, firms in the most innovative parts of the consumer software marketplace require a tight coupling and dependence between business decisions and software design ${ }^{[17]}$. It seems generally true that a small group of managers, such as founders and early employees, serve as both technology visionaries and business managers. Studying the decision and consensus processes in such organizations and how they relate to commercial success can bring insights useful in larger software firms and end-user firms in a variety of industries in making their software design decisions more business-relevant.

The idea of value co-creation within the user community of a consumer application $^{[14]}$ remarkably parallels the type of value that arises in informal interactions and collaborations within an organization. For example, in both cases the individuals are expected to spontaneously form networks, and generally there is no need or desire to directly monetize any value that results. Rather, the benefits are indirect, manifested by for example more usage and user loyalty in the consumer case and greater exploitation of tacit knowledge and increased employee loyalty in the organizational case. Studying the forms and origins of value in either case, as well as how those relate to the design and features of the software, can bring valuable insights to the other.

The epitome of open innovation in software is open source ${ }^{[26]}$, which has evolved from individual programmers to a collaborative method of software development among organizations. Both, but especially the individual contributions, are an example of end-user innovation ${ }^{[10]}$. While there has been considerable adoption of open-source solutions in enterprises, this has been mostly at the level of infrastructure (like operating systems or web servers) rather than applications. It remains largely unexplored whether open source would be a valuable modality for enterprises to share resources and expertise in application development ${ }^{[6]}$. Open source methodology and its predecessors have a long history in consumer application areas, and as such illustrate the potential.

Software development organizations have been adopting processes that are increasingly agile, embracing changing requirements and involving the end user more integrally in the design process ${ }^{[2],[18]}$. By all appearances many Web-based consumer applications have evolved at an unusually high rate, and tracked and benefited from user input and ideas to an unusual degree. It would be interesting to study their internal processes, which give the external appearance of agility. The extent to which processes are actually agile, and appreciating the mechanisms by which they are made agile, will require more empirical research. Clearly there is an opportunity to understand and capture and repurpose the techniques that have evolved. As well, consumer applications offer a good laboratory for experimenting with new ideas in development methodology.

While software distribution using software as a service (SaaS) ${ }^{[15]}$ appears in the vendor enterprise market, particularly in applications that target small to midsize businesses, consumer applications have carried this trend to a greater extreme, and their experience should be a valuable asset. In addition, IS organizations exploit SaaS- 
like approaches for serving internal users, and can be both a source of ideas and inspiration and a beneficiary of better practices in managing SaaS. For example, SaaS despite its many advantages suffers potential security vulnerabilities and data security issues $^{[4]}$ that must be overcome.

\section{Conclusions}

The consumer applications market offers a ripe opportunity for empirical research and as a laboratory for experimentation and qualification of new ideas in business models, user support, end-user innovation, and software development. This is particularly true of the large number of emerging Web-based applications and emerging models for software application distribution on mobile platforms. Since these areas are still emerging and maturing, they are strongly influenced by innovative new ideas. This can be a fruitful area for academic research within the management and software engineering disciplines for some years to come.

\section{References}

1. Alic, J. A., Branscomb, L. M., Brooks, H.: Beyond spinoff: Military and commercial technologies in a changing world. Harvard Business School Press (1992)

2. Beck, K., Beedle, M., van Bennekum, A. et al.: Manifesto for Agile Software Development. Available at http://agilemanifesto.org/

3. Chesbrough, H. W., Vanhaverbeke, W., West, J.: Open innovation: Researching a new paradigm. Oxford University Press, USA (2006)

4. Clark, D. L.: Enterprise security: The manager's defense guide. Addison-Wesley Professional (2002)

5. David, P. A.: The Dynamo and the Computer: An Historical Perspective on the Modern Productivity Paradox. American Economic Review, (1990) 355-361

6. Dreiling, A., Klaus, H., Rosemann, M. et al.: Open Source Enterprise Systems: Towards a Viable Alternative. Hawaii International Conference on Systems Science (2005) 227b$227 b$

7. Eraut, M.: Non-formal learning, implicit learning and tacit knowledge in professional work. In: Anonymous : The Necessity of Informal Learning. Policy Press (2000)

8. Graham, S. L., Snir, M., Patterson, C. A. (eds.): Getting up to speed: The future of supercomputing. National Academies Press (2005)

9. Hayes, B.: Cloud Computing. Communications of the ACM, 51 (2008)

10. Hippel, E.: Innovation by User Communities: Learning from Open-Source Software. MIT Sloan Management Review, 42 (2001) 82

11. Kraut, R. E., Fish, R. S., Root, R. W. et al.: Informal communication in organizations: Form, function, and technology. In: Baecker (ed.): Readings in Groupware and Computer-Supported Cooperative Work. Morgan Kaufman (1990) 145-199

12. Magerkurth, C., Cheok, A. D., Mandryk, R. L. et al.: Pervasive Games: Bringing Computer Entertainment Back to the Real World. Computers in Entertainment, 3 (2005) 4-4

13. Maznevski, M. L., \& Chudoba, K. M.: Bridging Space Over Time: Global Virtual Team Dynamics and Effectiveness. Organization Science, (2000) 473-492

14. Messerschmitt, D. G., Peltonen, J., Laine, M. O. J. et al.: Community Networked Services: Learning from Web 2.0. (2008) . Available at SSRN: http://ssrn.com/abstract=1320947 
15. Olsen, E. R.: Transitioning to Software as a Service: Realigning Software Engineering Practices with the New Business Model. IEEE International Conference on Service Operations and Logistics, and Informatics, (2006) 266-271

16. Österle, H., Fleisch, E., Alt, R.: Business networking: Shaping collaboration between enterprises. Springer (2001)

17. Peltonen, J., Messerschmitt, D., and Laine, M.: Web Business and Development Opportunities: Learning from Community Networked Services. Conference on Web Information Systems and Technologies, (2009)

18. Rajlich, V.: Changing the Paradigm of Software Engineering. Communications of the ACM, 49 (2006) 67-70

19. Ross, J. W., \& Feeny, D. F.: The Evolving Role of the CIO. Sloan School of Management Working paper 4089 (1999). Available at http://web.mit.edu/cisr/working\%20papers/cisrwp308.pdf

20. Stokes, D. E.: Pasteur's quadrant: Basic science and technological innovation. Brookings Institution Press (1997)

21. Teece, D. J.: Firm Organization, Industrial Structure, and Technological Innovation. Journal of Economic Behavior and Organization, 31 (1996) 193-224

22. Thomas, P., \& Macredie, R.: Games and the Design of Human-Computer Interfaces. Educational and Training Technology International, 31 (1994) 134-142

23. Turner, M., Budgen, D., Brereton, P.: Turning Software into a Service. IEEE Computer, 36 (2003) 38-44

24. von Hippel, E.: Democratizing innovation. MIT Press, Cambridge, Mass (2005)

25. von Hippel, E.: The sources of innovation. Oxford University Press, New York (1988)

26. West, J., \& Gallagher, S.: Patterns of open innovation in open source software. Oxford University Press, (2006) 